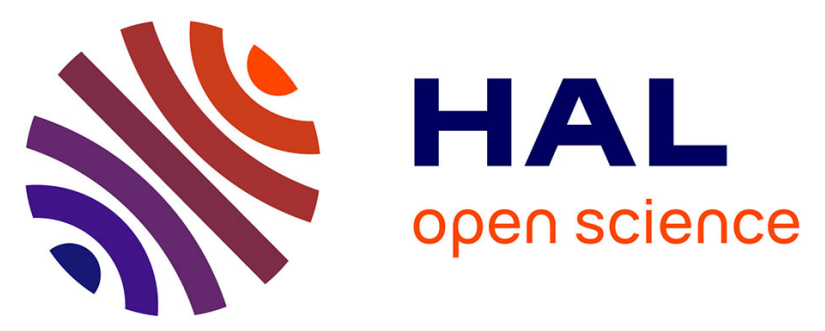

\title{
EXPANDING USAGES OF EARTH OBSERVATION DATA: A CO-DESIGN APPROACH TO GROW AN ECOSYSTEM OF EFFICIENT SERVICE DESIGNERS
}

Raphaëlle Barbier, Skander Ben Yahia, Pascal Le Masson, Benoit Weil

\section{- To cite this version:}

Raphaëlle Barbier, Skander Ben Yahia, Pascal Le Masson, Benoit Weil. EXPANDING USAGES OF EARTH OBSERVATION DATA: A CO-DESIGN APPROACH TO GROW AN ECOSYSTEM OF EFFICIENT SERVICE DESIGNERS. IEEE Geoscience and Remote Sensing Symposium (IGARSS), Jul 2021, Brussels, Belgium. hal-03356299

\section{HAL Id: hal-03356299 \\ https://hal.science/hal-03356299}

Submitted on 27 Sep 2021

HAL is a multi-disciplinary open access archive for the deposit and dissemination of scientific research documents, whether they are published or not. The documents may come from teaching and research institutions in France or abroad, or from public or private research centers.
L'archive ouverte pluridisciplinaire HAL, est destinée au dépôt et à la diffusion de documents scientifiques de niveau recherche, publiés ou non, émanant des établissements d'enseignement et de recherche français ou étrangers, des laboratoires publics ou privés. 


\title{
EXPANDING USAGES OF EARTH OBSERVATION DATA: A CO-DESIGN APPROACH TO GROW AN ECOSYSTEM OF EFFICIENT SERVICE DESIGNERS
}

\author{
Raphaëlle Barbier $^{(1)}$, Skander Ben Yahia ${ }^{(1)}$, Pascal Le Masson ${ }^{(1)}$, Benoit Weil( ${ }^{(1)}$ \\ ${ }^{(1)}$ Center for Management Science - i3 UMR CNRS 9217 - MINES ParisTech, PSL University / \\ ARMINES
}

\begin{abstract}
Earth Observation data has the potential to provide significant benefits to a large variety of socio-economic stakeholders. However, creating new usages of these data is particularly challenging as it requires connecting distant data and usages ecosystems. 'Co-designing' services based on Earth Observation data appears to be a promising path to overcome insufficiencies of 'open-data' strategies. However, in this challenging context, 'co-design' cannot be limited to the mere adjustment between user demands and data supply. Based on design theory, we propose a comprehensive framework for such a 'co-design' approach, aiming at growing an ecosystem of efficient service designers. It is experimented in the e-shape project. First results show that: (1) such co-design involves the implementation of a dynamic process of specific types of co-design actions, to unlock the different blocking points occurring in the growth of the ecosystem over time, (2) each co-design action aims at creating a 'resilient fit' between stakeholders.
\end{abstract}

Index Terms - co-design, Earth Observation, value creation from data, open-data, data-based ecosystems

\section{INTRODUCTION}

Earth Observation (EO) refers to the production of information about the planet and its environment, based on different types of instruments (satellites, in-situ sensors etc). Initially produced mainly for scientific goals, EO data are now made available to every economic actor, through 'open-data' policies. Socio-economic applications of this data seem to be diverse and promising, however, in practice, developing usages from EO data seems to be particularly challenging. Indeed, this effort could be schematically described as connecting very distant socio-economic ecosystems: the ecosystem of data and the various ecosystems of potential usages. These ecosystems are called "distant" as they do not share the same dynamics, time horizons (e.g. very long cycles to develop new instruments compared to short timeline of actions in the data usage context), performance logics and competencies (e.g. data processing might require very specific technical expertise while data usages might also require specific domain expertise).

In order to connect distant data and usages ecosystems, several approaches have been promoted and implemented by the EO community in the last decades. The first one consists in having each ecosystem bridging independently half the distance, through an 'open-data' strategy [1]: on the one side, data are made available to everyone, on the other side, the different stakeholders take advantage of these resources by integrating them in their own usage context. Despite being necessary to broaden the usages of data, this approach has proved to be insufficient, as the stakeholders tend to have difficulty making use of EO data spontaneously.

This accounts for the current efforts of the EO community to operate a second approach that consists in connecting the distant ecosystems of data and usages by encouraging the development of operational services based on Earth Observation data, through specific 'co-design' activities. An important stream of literature documents the implementation of such an approach in the case of climate services (based on climate-related data, being a certain type of EO data). Co-design (also referred as 'co-production' or 'co-development' depending on the authors) mostly relates to the involvement of data users in order to adjust user demands and the supply of useful information [2]. Without appropriate processes, this might lead to ad hoc small-scale and short-lived data-based services. However, despite being implemented in several projects through dedicated processes, recent research also underlines that what is understood by 'co-design' is not systematically discussed and formalized [3].

Based on the research work carried out in e-shape, a project funded within the EU Horizon 2020 program [4], this paper aims at proposing an analytical framework for codesign in the Earth Observation context, clarifying codesign ambitions and the operational tools that could effectively contribute to the expansion of EO data usages.

\section{CO-DESIGN SEEN FROM THE DESIGN AND MANAGEMENT FIELD}

Literature in design and in management gives interesting insights on different approaches of co-design and 
its evolution over time[5]. Co-design reported in the Earth observation field seems to mainly corresponds to a first approach consisting in building specific interactions between users and service designers in order to fit the developed service to user needs. This approach of co-design, as supply and demand adjustment, has largely developed since the years 2000s [6]. However, it is interesting to notice that co-design were previously used in completely different situations, aiming at addressing other blocking points of the development of products or services concerning actors other than the user:

- First, in the 70s, for the development of embedded systems [7]: co-design referred to hardware and software integration, as the issue was to make different fields of expertise cooperate, a list of requirement being already defined

- Later in the 90s, co-design referred to reshaping collaborations between buyers and suppliers, beyond usual price negotiation, to design new required components (e.g. in the automotive industry, new modules to increase comfort and reduce pollutant emission of cars) [8].

These elements lead us to make the following proposition regarding co-design in the Earth Observation context: co-design objective could be described as growing an ecosystem of efficient service designers by unlocking the different blocking points in the development of EO-based services, going beyond adjusting supply and demand between data users and service designers. This paper proposes to test this proposition based on e-shape experience, and to address the two resulting questions:

1. How to describe the blocking points occurring in the development of EO-based services?

2. What types of tools would be needed to unlock these blocking points?

\section{METHODOLOGY}

Our research relies on the work carried out within the EU-funded e-shape project, bringing together a team of 54 experienced partners from academia, industry, institutional entities and user communities to develop 27 pilot applications, spanning 7 thematic areas (food security, health, renewable energy, biodiversity, water resources, disaster resilience and climate). Given the large number of partners, and the variety of application sectors, e-shape appears to be a particularly favorable context to have a comprehensive understanding of the issues faced in the EO field. Within a dedicated work package led by the authors of the paper, a co-design approach is being progressively designed and experimented with e-shape partners, based on recent advances in design theory [9]. The following process has been set up to assess co-design needs for each pilot:

- Questionnaire sent to each pilot
- Answers used to classify the different blocking points faced by the pilots (also called "co-design needs") and make a first diagnosis for each pilot

- Interview of one hour and a half with each pilot to validate the diagnosis of co-design needs

\section{RESULTS}

The outcomes of this analysis process are summarized in Table 1 for 22 pilots (anonymized), the analysis of the 5 remaining pilots being still to be validated.

\begin{tabular}{|c|c|c|}
\hline & Short-term & Long-term \\
\hline Pilot & & \\
\hline \#1 & Type 1 & Type 3 \\
\hline \#2 & $\begin{array}{c}\text { Type } 1 \text { with User } 1 \\
\text { Type } 2 / 4\end{array}$ & $\begin{array}{c}\text { Type } 1 \text { with Users } 2 \& 3 \\
\text { Type } 3 \text { with partner }\end{array}$ \\
\hline$\# 3$ & Type $1 \& 2$ & Type 4 \\
\hline$\# 4$ & Type 1 & Type 4 \\
\hline$\# 5$ & Type 1 & Type $3 \& 4$ \\
\hline$\# 6$ & Type 1 & Type 2 for global scale \\
\hline$\# 7$ & Type $1 / 3 / 4$ & Type 4 \\
\hline$\# 8$ & Type 2 & Type 3 \\
\hline$\# 9$ & Type 1 & Type 4 \\
\hline$\# 10$ & Type $1 \& 4$ & Type 4 \\
\hline$\# 11$ & Type $1 \&$ Type 3 & Type 4 \\
\hline$\# 12$ & Type 2 & Type 1 \\
\hline$\# 13$ & Type $1 \&$ Type 4 & Type 4 \\
\hline$\# 14$ & Type 1 & Type 2 \\
\hline$\# 15$ & Type $1 /$ type 2 & Type $3 / 4$ \\
\hline$\# 16$ & Type $1 \& 3$ & Type 4 \\
\hline$\# 17$ & Type $1 \& 4$ & Type 4 \\
\hline$\# 18$ & Type 1 & Type $3 \& 4$ \\
\hline$\# 19$ & Type 3 & Type 4 \\
\hline$\# 20$ & Type 1 & Type 4 / Type 3 \\
\hline$\# 21$ & Type 1 & Type 4 \\
\hline$\# 22$ & Type 1 & Type 4 \\
\hline
\end{tabular}

Table 1: Analysis outcomes of e-shape pilots

\subsection{Co-design going beyond supply-demand adjustment}

A first noticeable result is the validation of the proposition according to which co-design needs are not restricted to adjusting supply and demand between data users and service designers. Indeed, this perspective only corresponds to a first type of co-design needs (referred as Type 1 in the Table 1), whereas three other types of codesign needs have also been identified. These four types of co-design needs correspond to four types of actions, each type corresponding to a certain blocking point requiring the design of the relationship with a specific actor (cf Table 2).

For each type, the initial state, blocking point to be addressed and expected outcomes always include two dimensions:

1. A dimension related to the design of the service, described with two terms usefulness and usability, as commonly used in literature on climate services[10]. Usefulness refers to the general potential seen by users, whereas usability refers to the effective integration in users' operations. Literature on climate services highlights that both aspects need to be addressed to successfully develop services, and that specific efforts are 
especially needed to move from useful to usable information, i.e. narrowing the so-called "usability gap".

2. A dimension related to the design of a specific relationship. This second dimension is crucial as the development of a service cannot be done only through collective work phases but also requires separate work phases. Agreeing on cooperation modalities is therefore crucial to guarantee the continuation of alternate collective and separate work phases over time. In a way, 'co-design' has to put a strong emphasis on designing the 'co', and not only the service itself.

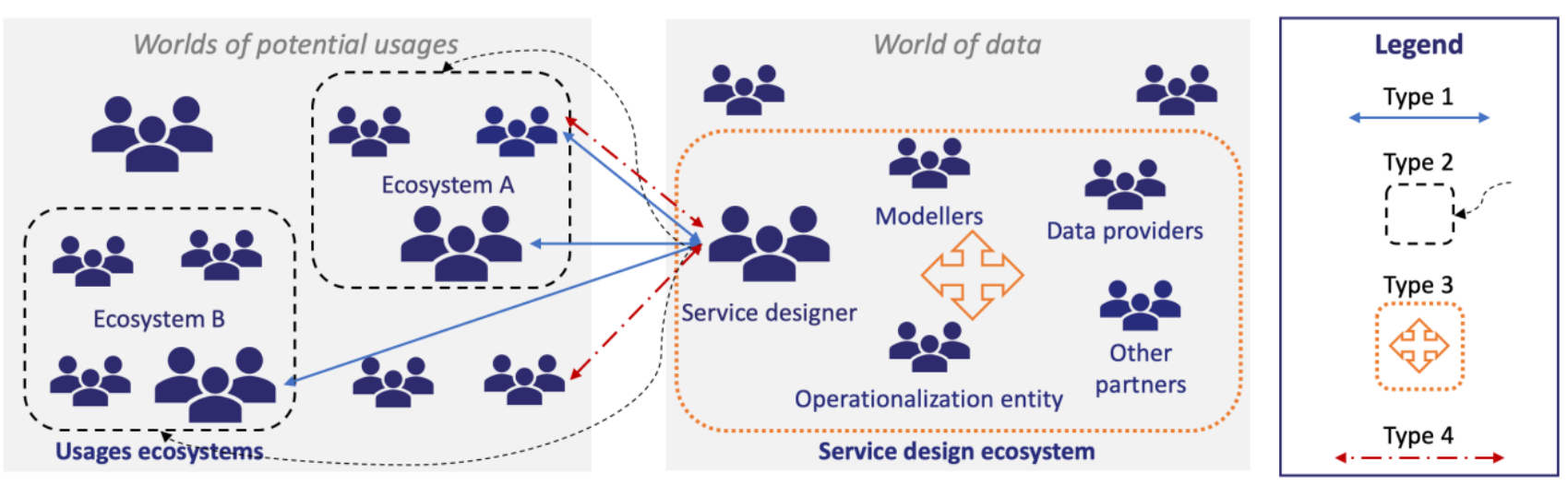

Figure 1: Schema of the four types of co-design actions aiming at connecting the distant data $\&$ usages ecosystems

\begin{tabular}{|c|c|c|c|c|c|c|}
\hline & Overall context & Initial state & $\begin{array}{c}\text { Blocking point to be } \\
\text { addressed }\end{array}$ & Expected outcomes & $\begin{array}{c}\text { "Quick-fit" } \\
\text { actions }\end{array}$ & "Resilient-fit" actions \\
\hline Type 1 & $\begin{array}{c}\text { Adjustment } \\
\text { between user and } \\
\text { service designer }\end{array}$ & $\begin{array}{l}\text { (a) Usefulness already } \\
\text { identified on a first basis } \\
\text { but to be enhanced. } \\
\text { Usability to be enhanced. } \\
\text { (b) Relationship with the } \\
\text { user to be precisely } \\
\text { defined but at least seems } \\
\text { favorable (user willing to } \\
\text { devote time settling it). }\end{array}$ & $\begin{array}{c}\text { Establishing adapted } \\
\text { relationships with } \\
\text { specific users for } \\
\text { usefulness \& usability } \\
\text { assessment and } \\
\text { enhancing }\end{array}$ & $\begin{array}{l}\text { (a) Enhanced lists of } \\
\text { requirements ensuring } \\
\text { usefulness and usability } \\
\text { (b) Cooperation modalities } \\
\text { with these specific users } \\
\text { clearly clearly formalized }\end{array}$ & $\begin{array}{l}\text { Finding ONE } \\
\text { satisfying list of } \\
\text { requirements with } \\
\text { one specific user }\end{array}$ & $\begin{array}{l}\text { In order to end up with a robust } \\
\text { list of requirements, exploring a } \\
\text { range of potential lists of } \\
\text { requirements and related } \\
\text { cooperation modalities allows a } \\
\text { better adaptation to surprises or } \\
\text { external constraints }\end{array}$ \\
\hline Type 2 & $\begin{array}{l}\text { Exploration for } \\
\text { usage initiation }\end{array}$ & $\begin{array}{l}\text { (a) Usefulness not well- } \\
\text { known and/or } \\
\text { (b) Relationship with the } \\
\text { user appearing to be } \\
\text { difficult to establish } \\
\text { (uncommitted users) }\end{array}$ & $\begin{array}{c}\text { Establishing adapted } \\
\text { interactions with user } \\
\text { communities for } \\
\text { usefulness } \\
\text { identification }\end{array}$ & $\begin{array}{l}\text { (a) Expanded usefulness of } \\
\text { the service } \\
\text { (b) Expanded list of } \\
\text { relevant stakeholders to } \\
\text { interact with }\end{array}$ & $\begin{array}{l}\text { Finding a new } \\
\text { relevant user to } \\
\text { interact with }\end{array}$ & $\begin{array}{l}\text { Building relationships with a } \\
\text { portfolio of relevant actors with a } \\
\text { minimal usefulness established }\end{array}$ \\
\hline Type 3 & $\begin{array}{c}\text { Engineering for } \\
\text { operationalization }\end{array}$ & $\begin{array}{l}\text { (a) Lists of requirements } \\
\text { for usefulness and } \\
\text { usability established. } \\
\text { (b)Relationships with } \\
\text { users established. }\end{array}$ & $\begin{array}{c}\text { Establishing adapted } \\
\text { relationships with } \\
\text { relevant partners for } \\
\text { extensive usefulness \& } \\
\text { usability realization } \\
\text { and operationalization } \\
\text { of the service }\end{array}$ & \begin{tabular}{|} 
(a) Clarification of the \\
service structure (parts \\
ready to be operationalized, \\
parts needing further \\
exploration) \\
(b) Cooperation modalities \\
between R\&D and \\
operationalization entities \\
clearly formalized
\end{tabular} & $\begin{array}{l}\text { Building the } \\
\text { technical } \\
\text { infrastructure for an } \\
\text { existing user }\end{array}$ & $\begin{array}{l}\text { Structuring the service offer for a } \\
\text { range of users and building all } \\
\text { required resources through } \\
\text { adapted partnerships }\end{array}$ \\
\hline Type 4 & $\begin{array}{l}\text { Exploration for } \\
\text { usage expansion }\end{array}$ & $\begin{array}{l}\text { Usefulness, usability and } \\
\text { relationships already } \\
\text { established with existing } \\
\text { users. }\end{array}$ & \begin{tabular}{|} 
Establishing adapted \\
relationships with \\
existing \& potential \\
new users for \\
usefulness reinvention
\end{tabular} & \begin{tabular}{|} 
(a) Expanded range of \\
potential alternatives for \\
future usages (which \\
usefulness for which actors) \\
(b) Cooperation modalities \\
and supports for \\
interactions (proofs-of- \\
concept) defined for \\
existing and new users
\end{tabular} & $\begin{array}{l}\text { Merely asking } \\
\text { existing users what } \\
\text { they would dream } \\
\text { of }\end{array}$ & $\begin{array}{l}\text { Setting-up a joint programme for } \\
\text { long-term exploration of new } \\
\text { usages (identification of } \\
\text { obstacles, research efforts to be } \\
\text { made, etc) }\end{array}$ \\
\hline
\end{tabular}

Table 2: Characterization of each co-design type and related actions 
4.2. Co-design as a dynamic interplay of four types of actions to connect distant data and usages ecosystems

A second major result is the consideration of codesign as a dynamic interplay of these four types of actions. It is first an interplay of actions because at every moment, each service designer might be confronted with several codesign needs. For example, the service designer might at the same time need a co-design type 1 to strengthen the relationship with a certain user, but also consider a type 2 to explore a new type of user community, and prepare for the operationalization of the service through a type 3. This interplay is also dynamic because each service designer goes through different co-design types at different moments in time, depending on its evolution and the issues faced all along. This appears in Table 1 through the integration of both short-term and long-term time horizons.

\subsection{Implementation of specific tools for each type of action, in a "resilient-fit" perspective}

A third important result concerns the type of tools needed to support these four types of actions. It was first noticed that e-shape partners were already experienced in making some parts of these actions on their own, however they were often faced with the issue of making these efforts of connecting data and usages sustainable over time. Consequently, it appears that specific tools are required, aiming at establishing a "resilient fit" between stakeholders, rather than a "quick fit".

"Quick-fit" actions only focus on finding one type of interaction between data and usages ecosystems (single list of requirements with one user, in a punctual relationship). Whereas, "resilient-fit" actions aim at generating a range of alternatives (regarding the lists of requirements, the stakeholders involved, the types of partnerships), allowing a better adaptation to future surprises or unexpected constraints arising later in the process. These specific tools for "resilient-fit" actions are currently under experimentation within e-shape, but illustrations of "quickfit" and "resilient-fit" actions are already given for each type of co-design in Table 2.

\section{CONCLUSION}

This paper introduces an analytical framework for co-design adapted to the Earth Observation context, that has been designed and experimented within e-shape. The overall ambition of such a co-design approach is to progressively connect and expand the distant ecosystems of data and usages. In this perspective, we highlighted that co-design should not be restricted to the adjustment of supply and demand between users and service designers, but should be considered as a way of growing an ecosystem of efficient
EO-based service designers. It is based on a continuous process involving four types of actions aiming at unlocking blocking points occurring in the development of the services. Each type corresponds to the design of a certain committed form of relationship and should target a "resilient fit" between relevant stakeholders, in order to make sure that these efforts are sustainable over time. This approach of co-design and the related tools will be further experimented in the coming years within e-shape.

\section{ACKNOWLEDGMENT}

This project has received funding from the European Union's Horizon 2020 research and innovation programme under grant agreement No 820852.

\section{REFERENCES}

[1] M. T. Borzacchiello and M. Craglia, 'The impact on innovation of open access to spatial environmental information: a research strategy', International Journal of Technology Management, vol. 60, no. 1/2, p. 114, 2012

[2] E. C. McNie, 'Delivering Climate Services: Organizational Strategies and Approaches for Producing Useful ClimateScience Information', Weather, Climate, and Society, vol. 5, no. 1, pp. 14-26, Jan. 2012

[3] C. M. Goodess et al., 'Advancing climate services for the European renewable energy sector through capacity building and user engagement', Climate Services, vol. 16, p. 100139, Dec. 2019,

[4] T. Ranchin, L. Ménard, Fichaux, Nicolas, Reboul, Mathieu, and all e-shape partners, 'e-shape - EuroGEO Showcases: application powered by Europe contribution to EuroGEO and to the development of the EO industry', IGARSS 2021, Brussels, Belgium, Jul. 2021.

[5] L.-E. Dubois, P. Le Masson, B. Weil, and P. Cohendet, 'From organizing for innovation to innovating for organization: how co-design fosters change in organizations.', International Product Development Management Conference, Limerick, Ireland, 2014.

[6] M. Steen, 'Co-Design as a Process of Joint Inquiry and Imagination', Design Issues, vol. 29, no. 2, pp. 16-28, Apr. 2013

[7] W. H. Wolf, 'Hardware-software co-design of embedded systems', Proceedings of the IEEE, vol. 82, no. 7, pp. 967989, Jul. 1994

[8] G. Spina, R. Verganti, and G. Zotteri, 'Factors influencing co-design adoption: drivers and internal consistency', International Journal of Operations \& Production Management, vol. 22, no. 12, pp. 1354-1366, Jan. 2002

[9] P. Le Masson, B. Weil, and A. Hatchuel, Design Theory: Methods and Organization for Innovation. Springer International Publishing, 2017.

[10] M. C. Lemos, C. J. Kirchhoff, and V. Ramprasad, 'Narrowing the climate information usability gap', Nature Climate Change, vol. 2, no. 11, pp. 789-794, Nov. 2012 